\title{
When beta cells talk back
}

\author{
Heather C. Denroche ${ }^{1}$ Dominika Nackiewicz ${ }^{1}$ C. Bruce Verchere ${ }^{1,2}$
}

Received: 4 August 2017 / Accepted: 9 August 2017 /Published online: 20 September 2017

(C) Springer-Verlag GmbH Germany 2017

Keywords ATP · Beta cell · Inflammation · Insulin · Islet . Macrophage $\cdot$ Purinergic

\section{Abbreviations \\ GABA $\gamma$-Aminobutyric acid \\ IAPP Islet amyloid polypeptide \\ MMP Matrix metalloproteinase}

\section{Introduction}

Islet macrophages reside in the perivascular space next to islet blood vessels. They are long-lived and self-renewing, maintaining about two to ten macrophages per islet [1]. However, more than three decades after the first description of islet macrophages [2], our knowledge regarding the biological role of these cells is limited (reviewed in [3]). Emerging evidence indicates that islet macrophages are important for islet homeostasis and secrete numerous factors that modulate beta cell activity. Reciprocally, in this issue of Diabetologia, Weitz et al demonstrate that a factor secreted by beta cells is sensed by islet macrophages [4], revealing the

C. Bruce Verchere bverchere@bcchr.ca

1 Department of Surgery, BC Children's Hospital Research Institute, University of British Columbia, 950 W 28 Ave, Vancouver V5Z 4H4, Canada

2 Department of Pathology and Laboratory Medicine, BC Children's Hospital Research Institute, University of British Columbia, Vancouver, Canada possibility of a physiological, two-way dialogue between islet macrophages and pancreatic beta cells (Fig. 1).

\section{Islet macrophages in health and disease}

Perhaps the most well-recognised relationship between islet macrophages and beta cells is a deleterious one: the contribution of islet macrophages to islet inflammation and beta cell death and dysfunction in both type 1 and type 2 diabetes. Macrophages and proinflammatory cytokines are increased in the islets of individuals with type 2 diabetes [5, 6]. In response to various danger signals that are elevated in diabetes, including toll-like receptor agonists, NEFAs, endocannabinoids and islet amyloid polypeptide (IAPP) aggregates, to name a few, macrophages secrete proinflammatory cytokines [7-11]. Beta cell dysfunction during islet inflammation is mediated by several cytokines, including IL- $1 \beta$ and TNF $\alpha$, for which islet macrophages are the primary source within inflamed islets [12]. Macrophages are also important effectors mediating beta cell death in models of type 1 diabetes $[13,14]$. Collectively, this has earned islet macrophages a 'bad guy' reputation in the islet.

Though partaking in beta cell demise in pathological conditions, islet macrophages can also support beta cell function and proliferation. For example, while chronic exposure to IL-1 $\beta$ secreted from islet macrophages during inflammation is toxic to beta cells, acute, low concentrations of IL-1 $\beta$ have an insulinotropic effect on beta cells and play an important role in augmenting insulin secretion during acute stresses and in the postprandial state $[15,16]$. Like other resident macrophages, islet macrophages are also likely to be important in phagocytosing dead or dying cells and debris and maintaining islet cell homeostasis. Islet macrophages continuously sample antigen from beta cells [17] and, through 


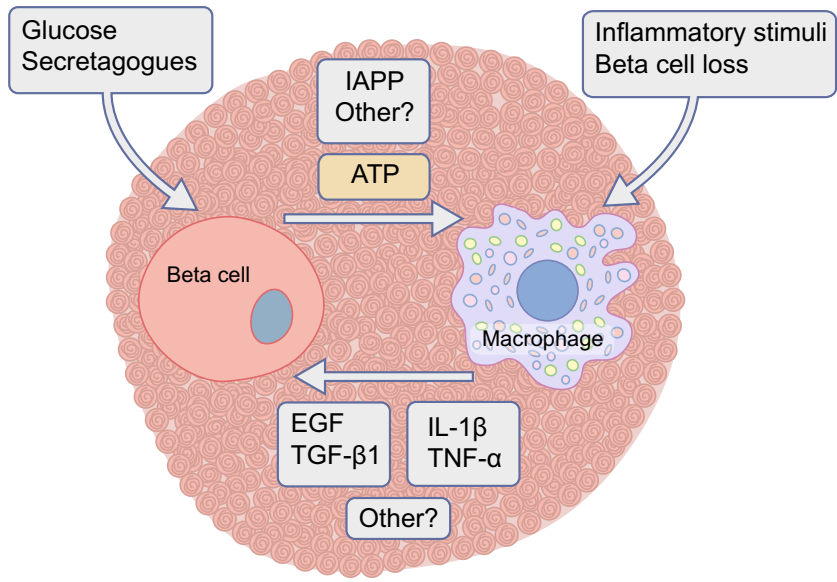

Fig. 1 Crosstalk between beta cells and islet macrophages. In response to various stimuli originating within and outside of the islet, macrophages release signals that influence beta cell function. IL- $1 \beta$ and TNF- $\alpha$ are released by macrophages under inflammatory and postprandial conditions; these act on the beta cell to alter insulin production and secretion and, with chronic exposure, can lead to beta cell dysfunction. Several regenerative factors, which promote beta cell proliferation, including EGF and TGF- $\beta 1$, are released by islet macrophages in response to beta cell loss. Likewise, beta cells release signals that act on islet macrophages. In diabetes IAPP aggregates originating from beta cells activate inflammatory responses in macrophages. In this issue, Weitz et al [4] demonstrate that ATP, co-released from beta cells during insulin secretion, is sensed by macrophages. The outcome of this signal on macrophage function is unknown. Additional signals may exist between islet macrophages and beta cells that have not yet been identified

surveying the blood vessels and islet milieu for danger signals and invading pathogens, also act as an important first line of immunological defence. Mice lacking tissue resident macrophages have reduced beta cell mass [18] and, more recently, macrophages have been found to play an important role in beta cell proliferation and regeneration in models of acute beta cell loss [19-21]. Many proliferative factors are released by macrophages, among them transforming growth factor $\beta$ (TGF $\beta 1$ ) and EGF, which were reported to mediate beta cell regeneration following pancreatic duct ligation [21]. Moreover, macrophages were shown to be crucial for beta cell proliferation following vascular endothelial growth factor-A mediated beta cell reduction [19], and for beta cell regeneration mediated by connective tissue growth factor following pancreatic ductal ligation [20].

\section{Beta cell-islet macrophage crosstalk}

Whether it be inflammatory cytokines in diabetes, or proliferation cues under regenerative states, the islet macrophage clearly provides numerous signals that modify beta cell behaviour and survival. This begs the question, do beta cells talk back to islet macrophages? Evidence exists for chronic beta cell-derived cues that macrophages respond to, including the accumulation of IAPP aggregates in type 2 diabetes, which induce a robust inflammatory response [8, 9, 12]. Intriguingly, intact insulin granules have also been observed within islet macrophages, indicative of an intimate interaction between these cell types [17].

In this issue, Weitz et al [4] use an innovative technique to probe a simple question: which, if any, pancreatic cell-derived signals acutely activate islet macrophages under physiological conditions? The authors developed and employed an in situ imaging technique by which intracellular calcium responses in pancreatic macrophages were visualised in live pancreas slices, using mice that express a fluorescent calcium indicator, GCaMP3 (a green fluorescent protein [GFP]-calmodulin fusion), following Cre-mediated recombination. The authors used several myeloid-lineage Cre lines to induce GCaMP3 expression in macrophages, and examined macrophage calcium responses in live pancreas slices under a range of stimuli.

Under high glucose concentrations to stimulate insulin secretion from beta cells, Weitz et al found that calcium signals were activated in pancreatic macrophages, indicating activation by a factor secreted by beta cells. This was mimicked by application of $\mathrm{KCl}$ to induce secretion from islet endocrine cells. The authors verified that activation was dependent on beta cell secretion by applying an inhibitor of L-type voltage gated calcium channels to inhibit insulin secretion, which prevented glucose induced activation of islet macrophages. To elucidate the beta cell-derived signal responsible for activation, the authors applied ATP, $\gamma$ aminobutyric acid (GABA) or serotonin (all of which are coreleased from insulin granules) to pancreas slices. ATP, but not GABA or serotonin, mimicked the activation of pancreatic macrophages by high glucose. Similarly, purinergic receptor agonists were found to elicit macrophage calcium responses, and several purinergic $\mathrm{P} 2 \mathrm{Y}$ and $\mathrm{P} 2 \mathrm{X}$ receptors were highly expressed on sorted $\left(\mathrm{GFP}^{+}\right.$and $\left.\mathrm{F} 4 / 80^{+}\right)$islet macrophages. Importantly, the activation of pancreatic macrophages under high glucose conditions was blocked by co-application of the purinergic P2 receptor antagonist, suramin. Islet macrophages also responded more potently to high glucose than acinar macrophages, consistent with these cells being exposed to greater ATP concentrations because of their proximity to beta cells. Taken together, these findings reveal that ATP, coreleased from beta cells during insulin secretion, activates islet macrophages in a paracrine manner through purinergic receptor signalling.

The findings of Weitz and colleagues imply that, through the co-release of ATP from insulin granules, macrophages may be able to acutely sense beta cell secretory status. Owing to islet macrophage paucity relative to other islet cells, studying these cells is challenging and generally requires an isolation procedure to enrich for islet macrophages, adding the risk of altering macrophage phenotype and behaviour. A major strength of the current study is the use of in situ 
imaging, leaving the resident islet macrophages within their intact environment. Furthermore, this study examined islet macrophages under normal conditions, whereas most studies have focused on models of inflammation, autoimmunity or beta cell injury. The next obvious question from this study is what is the response of islet macrophages to beta cell-secreted ATP, and what is the physiological role of this signal? The authors performed a cursory examination of the impact of acute ATP signalling in sorted islet macrophages, and found decreased expression of the gene encoding matrix metalloproteinase (MMP)-2 (Mmp2). ATP also elicited increased pseudopodia movement of macrophages, but this effect was not observed under high glucose, suggesting that this is not an effect of ATP secreted from beta cells under physiological conditions. Purinergic signalling has been shown to acutely modify macrophage activity in other tissues (reviewed in [22]), but further study is needed to elucidate the role of ATP sensing in islet macrophages.

According to current knowledge, monocytes and macrophages express ionotropic P2X receptors and G-proteincoupled P2Y receptors [23]. In human monocytes, genes encoding the P2X receptors $P 2 R X 4, P 2 R X 1$ and $P 2 R X 7$, and the P2Y receptors $P 2 R Y 2, P 2 R Y 13$ and $P 2 R Y 11$ are highly expressed [24]. In murine islet macrophages, Weitz et al detected expression of P2rx4, P2rx7, P2ry2, P2ry6, P2ry14, and the P1 receptors Adoral, Adora2a, Adora2b and Adora3 [4]. These purinergic receptors are involved in a variety of macrophage responses. For example, $\mathrm{P} 2 \mathrm{X}_{7}$ receptor signalling is implicated in the maturation and release of IL-1 $\beta / I L-18$ via the NACHT, LRR and PYD domains-containing protein 3 (NLRP3) inflammasome [25], the release of prostaglandin E2 (PGE2) and MMP-9 [26, 27], and together with $\mathrm{P}_{2} \mathrm{X}_{4}$ receptors, the regulation of autophagy [28]. Many of the $\mathrm{P} 2$ receptors are responsible for intracellular calcium increase [29]. Furthermore, these receptors are sensors of so-called 'find-me' signals from cells that are in distress and can propagate further chemotactic and excitatory effects on immune cells [30].

\section{Summary}

The study by Weitz et al in this issue of Diabetologia [4] identifies ATP as an acute paracrine signal released from beta cells that activates islet macrophages, thus revealing the possibility of an ongoing, two-way dialogue between beta cells and islet macrophages. As this study focussed on calcium responses in macrophages, it is possible that beta cells also provide calcium-independent cues to macrophages. There is still much to understand about the interaction between beta cells and islet macrophages, but it is becoming increasingly clear that macrophages are important partners in islet homeostasis, playing an ongoing role in beta cell health and disease by communicating with and receiving signals from beta cells. How the dialogue between beta cells and islet macrophages proceeds throughout life, and the implications of this complex interaction, remain a warranted yet underexplored frontier, pursuit of which will hopefully be stimulated by this elegant study by Weitz and colleagues.

Funding Work in the authors' laboratories is supported by the Canadian Institutes of Health Research (CIHR), the JDRF, and the Stem Cell Network. HCD was supported by a JDRF Postdoctoral Fellowship and a Diabetes Canada Postdoctoral Fellowship. DN was supported by a Vanier Canada Graduate Scholarship. CBV is supported by an investigator award from BC Children's Hospital and the Irving K. Barber Chair in Diabetes Research.

Duality of interest The authors declare that there is no duality of interest associated with this manuscript.

Contribution statement All authors were responsible for drafting the article and revising it critically for important intellectual content. All authors approved the version to be published.

\section{References}

1. Calderon B, Carrero JA, Ferris ST et al (2015) The pancreas anatomy conditions the origin and properties of resident macrophages. J Exp Med 212:1497-1512

2. Hume DA, Halpin D, Charlton H, Gordon S (1984) The mononuclear phagocyte system of the mouse defined by immunohistochemical localization of antigen F4/80: macrophages of endocrine organs. Proc Natl Acad Sci 81:4174-4177

3. Morris DL (2015) Minireview: emerging concepts in islet macrophage biology in type 2 diabetes. Mol Endocrinol 29:946-962

4. Weitz JR, Makhmutova M, Almaça J et al (2017) Mouse pancreatic islet macrophages use locally released ATP to monitor beta cell activity. Diabetologia https://doi.org/10.1007/s00125-017-4416-y

5. Ehses JA, Perren A, Eppler E et al (2007) Increased number of isletassociated macrophages in type 2 diabetes. Diabetes 56:2356-2370

6. Böni-Schnetzler M, Thorne J, Parnaud G et al (2008) Increased interleukin (IL)- $1 \beta$ messenger ribonucleic acid expression in $\beta$ cells of individuals with type 2 diabetes and regulation of IL-1 $\beta$ in human islets by glucose and autostimulation. J Clin Endocrinol Metab 93:4065-4074

7. Nackiewicz D, Dan M, He W et al (2014) TLR2/6 and TLR4activated macrophages contribute to islet inflammation and impair beta cell insulin gene expression via IL-1 and IL-6. Diabetologia 57:1645-1654

8. Westwell-Roper C, Dai DL, Soukhatcheva G et al (2011) IL-1 blockade attenuates islet amyloid polypeptide-induced proinflammatory cytokine release and pancreatic islet graft dysfunction. J Immunol 187:2755-2765

9. Masters SL, Dunne A, Subramanian SL et al (2010) Activation of the NLRP3 inflammasome by islet amyloid polypeptide provides a mechanism for enhanced IL- $1 \beta$ in type 2 diabetes. Nat Immunol 11:897-904

10. Wen H, Gris D, Lei Y et al (2011) Fatty acid-induced NLRP3-ASC inflammasome activation interferes with insulin signaling. Nat Immunol 12:408-415 
11. Jourdan T, Godlewski G, Cinar R et al (2013) Activation of the Nlrp3 inflammasome in infiltrating macrophages by endocannabinoids mediates beta cell loss in type 2 diabetes. Nat Med 19:1132-1140

12. Westwell-Roper CY, Ehses JA, Verchere CB (2014) Resident macrophages mediate islet amyloid polypeptide-induced islet IL$1 \beta$ production and $\beta$-cell dysfunction. Diabetes 63:1698-1711

13. Calderon B, Suri A, Unanue ER (2006) In CD4+ T cell-induced diabetes, macrophages are the final effector cells that mediate islet $\beta$-cell killing. Am J Pathol 169:2137-2147

14. Kolb H, Burkart V, Appels B et al (1990) Essential contribution of macrophages to islet cell destruction in vivo and in vitro. J Autoimmun 3(Suppl 1):117-120

15. Hajmrle C, Smith N, Spigelman AF et al (2016) Interleukin-1 signaling contributes to acute islet compensation. JCI Insight 1:1-14

16. Dror E, Dalmas E, Meier DT et al (2017) Postprandial macrophagederived IL- $1 \beta$ stimulates insulin, and both synergistically promote glucose disposal and inflammation. Nat Immunol 18:283-292

17. Vomund AN, Zinselmeyer BH, Hughes J et al (2015) Beta cells transfer vesicles containing insulin to phagocytes for presentation to T cells. Proc Natl Acad Sci U S A 112:E5496-E5502

18. Banaei-Bouchareb L, Gouon-Evans V, Samara-Boustani D et al (2004) Insulin cell mass is altered in Csflop/Csflop macrophagedeficient mice. J Leukoc Biol 76:359-367

19. Brissova M, Aamodt K, Brahmachary P et al (2014) Islet micro environment,modulated by vascular endothelial growth factor-A signaling, promotes beta cell regeneration. Cell Metab 19:498-511

20. Riley KG, Pasek RC, Maulis MF et al (2015) Macrophages are essential for CTGF-mediated adult $\beta$-cell proliferation after injury. Mol Metab 4:584-591
21. Xiao X, Gaffar I, Guo P et al (2014) M2 macrophages promote beta-cell proliferation by up-regulation of SMAD7. Proc Natl Acad Sci U S A 111:E1211-E1220

22. Cekic C, Linden J (2016) Purinergic regulation of the immune system. Nat Rev Immunol 16:177-192

23. Jacob F, Novo CP, Bachert C, Van Crombruggen K (2013) Purinergic signaling in inflammatory cells: $\mathrm{P} 2$ receptor expression, functional effects, and modulation of inflammatory responses. Purinergic Signal 9:285-306

24. Wang L, Jacobsen SEW, Bengtsson A, Erlinge D (2004) P2 receptor mRNA expression profiles in human lymphocytes, monocytes and CD34+ stem and progenitor cells. BMC Immunol 5:16

25. Giuliani AL, Sarti AC, Falzoni S, Di Virgilio F (2017) The P2X7 receptor-interleukin-1 liaison. Front Pharmacol 8:123

26. Gu BJ, Wiley JS (2006) Rapid ATP-induced release of matrix metalloproteinase 9 is mediated by the $\mathrm{P} 2 \mathrm{X} 7$ receptor. Blood 107: 4946-4953

27. Barbera-Cremades M, Baroja-Mazo A, Gomez AI, Machado F, Di Virgilio F, Plegrín P (2012) P2X7 receptor-stimulation causes fever via PGE2 and IL-1 release. FASEB J 26:2951-2962

28. Kawano A, Tsukimoto M, Mori D et al (2012) Regulation of P2X7dependent inflammatory functions by $\mathrm{P} 2 \mathrm{X} 4$ receptor in mouse macrophages. Biochem Biophys Res Commun 420:102-107

29. Idzko M, Hammad H, van Nimwegen M et al (2007) Extracellular ATP triggers and maintains asthmatic airway inflammation by activating dendritic cells. Nat Med 13:913-919

30. Elliott MR, Chekeni FB, Trampont PC et al (2009) Nucleotides released by apoptotic cells act as a find-me signal to promote phagocytic clearance. Nature 461:282-286 